\title{
Pulmonary and Systemic Induction of SAA3 After Ventilation and Endotoxin in Preterm Lambs
}

\author{
TEICHA C. WILSON, CINDY J. BACHURSKI, MACHIKO IKEGAMI, ALAN H. JOBE, \\ AND SUHAS G. KALLAPUR \\ Cincinnati Children's Hospital Medical Center, University of Cincinnati College of Medicine, Division of \\ Pulmonary Biology [T.C.W., C.J.B., M.I., A.H.J., S.G.K.], 3333 Burnet Avenue, Cincinnati, OH 45229
}

\begin{abstract}
Serum amyloid A (SAA), an acute phase reactant (APR) protein, is induced in liver during systemic inflammation. Serum amyloid A3 (SAA3), an isoform of SAA, is induced in both liver and extra hepatic sites in response to proinflammatory stimuli such as cytokines. Previously, we showed a modest increase in plasma cytokine levels in a preterm lamb model of lung injury. The study objective was to determine the relative contributions of lung and liver to the acute phase response during postnatal lung injury. Preterm (130d) and near term (141d) newborn lambs (term $=150 \mathrm{~d})$ were randomized to either no ventilation (controls), ventilation + intratracheal (IT) endotoxin (endo) or ventilation + IT saline. A group of near term lambs were exposed to ventilation + IV endotoxin. In the lungs, ventilation alone increased SAA3 mRNA 3- and 13-fold while ventilation + IT endotoxin increased SAA3 mRNA 64 and 366-fold above controls in preterm and near term lambs, respectively. In the liver, SAA3 mRNA was induced by ventilation alone (three-fold) and ventilation + IT endotoxin (45-fold) above controls in both
\end{abstract}

\section{ABSTRACT}

preterm and near term animals. Ventilation + IV endotoxin caused the highest increase in SAA3 mRNA (212-fold) in the liver of near term animals. A different isoform, identified as SAA-Liver inducible was maximally induced in liver by ventilation alone with minimal further response to endotoxin. Lung SAA3 mRNA expression was detected primarily in airway epithelium, bronchial glands, perichondrium of bronchial cartilage and vascular smooth muscle cells. Our experiments show rapid induction of an APR gene in lung in response to proinflammatory stimuli. (Pediatr Res 58: 1204-1209, 2005)
APR, acute phase reactant
BAL, bronchoalveolar lavage
IT, intratracheal
IV, intravenous

Abbreviations

SAA, serum amyloid A

SAA-Li, serum amyloid A-liver inducible
The acute phase of the systemic inflammatory response is characterized by the hepatic synthesis and increased plasma concentrations of acute phase reactants (APR) such as heat shock proteins, $\mathrm{C}$ reactive protein (CRP), and the serum amyloids (1-3). The serum amyloid A family of proteins is one of the major APR whose plasma levels can increase up to 1000fold in response to inflammation (4). Several isoforms of the SAA protein are conserved across species. The liver is the main source of SAA1 and SAA2 isoforms whereas SAA3 isoform expression is increased in liver as well as extra hepatic tissues (4-7). We identified SAA3 as an endotoxin inducible gene in the fetal lung using subtraction hybridization of endotoxin versus saline exposed lung mRNA (8). No information is

Received January 4, 2005; accepted June 1, 2005.

Correspondence: Suhas G. Kallapur, M.D., Cincinnati Children's Hospital Medical Center, Division of Pulmonary Biology, 3333 Burnet Avenue, Cincinnati, OH 452293039; email: suhas.kallapur@cchmc.org

This work was supported by National Institutes of Health grants HD 12714, HL 65397 and K08 HL 70711.

DOI: $10.1203 / 01 . p d r .0000185269 .93228 .29$ available regarding the biology of SAA3 in preterm newborn animals exposed to postnatal lung injury induced by mechanical ventilation, oxygen or endotoxin.

Mechanical ventilation and pulmonary infections frequently cause lung injury in preterm infants. Mechanical ventilation contributes to neonatal morbidity and mortality $(9,10)$ by causing lung inflammation with the induction of the proinflammatory cytokine cascade (11-13). Intratracheal endotoxin induces both lung inflammation and a systemic inflammatory response in preterm and term ventilated lambs (14). Whether there is induction of a lung acute phase reactant response in these models is not known. Furthermore, the occurrence of a systemic acute phase reactant response on lung exposure to pro-inflammatory stimuli is not well characterized. We hypothesized that SAA3 mRNA expression would increase in the preterm newborn lung postnatally exposed to proinflammatory stimuli. We, therefore, examined the effect of mechanical ventilation with or without endotoxin exposure on SAA3 mRNA induction in preterm and near term lamb lungs and contrasted the lung responses to the liver responses. In 
addition, we characterized the sites of induced expression of SAA3 mRNA in lung.

\section{METHODS}

Animals and ventilator strategy. The tissue samples from the preterm (130d GA) and near term lambs (141d GA) used for these experiments were previously used for traditional assessments of lung inflammation (14). The protocols were approved by the Animal Care and Use Committee of the Cincinnati Children's Hospital Research Foundation. The lambs were delivered by cesarean section and randomized to receive either $10 \mathrm{mg} / \mathrm{kg}$ of endotoxin (Escherichia coli 055:B5; Sigma Chemical Co. Chemicals, St. Louis, $\mathrm{MO}$ ) or identical volumes of saline intratracheally at delivery before the first breath. The preterm animals received endotoxin mixed with $100 \mathrm{mg} / \mathrm{kg}$ surfactant (Venticute; Byk Gulden, Konstanz, Germany) containing 2\% recombinant human SP-C in phospholipids (15). To characterize the systemic response to endotoxin, another group of near term animals was given intravascular endotoxin $(5 \mu \mathrm{g} / \mathrm{kg})$ at delivery. The lambs were ventilated for $6 \mathrm{~h}$ using time-cycled, pressure limited infant ventilators (Sechrist Industries, Anaheim, CA). The initial ventilator settings included fraction of inspired oxygen $\left(\mathrm{FIO}_{2}\right)$ : 1.0 ; inspiratory time: $0.6 \mathrm{~s}$; positive end-expiratory pressure (PEEP): $4 \mathrm{~cm} \mathrm{H}_{2} \mathrm{O}$ and a peak inspiratory pressure (PIP) sufficient to obtain a target tidal volume $\left(\mathrm{V}_{\mathrm{T}}\right)$ of about $10 \mathrm{~mL} / \mathrm{kg}$. The PIP was limited to $35 \mathrm{~cm} \mathrm{H}_{2} \mathrm{O}$ to decrease the risk of pneumothorax. Subsequently, to minimize lung injury, the ventilatory pressure (PIP-PEEP) and $\mathrm{FIO}_{2}$ were adjusted to achieve a target $\mathrm{PaCO}_{2}$ of $45-55 \mathrm{~mm} \mathrm{Hg}$ and $\mathrm{PaO}_{2}$ of $150-200 \mathrm{~mm} \mathrm{Hg}$. Higher airway pressures were needed for the preterm compared with the near term animals to maintain the target $\mathrm{PaCO}_{2}$ values (14). Control groups of gestation-matched lambs were not ventilated. Comparisons were made between treated animals at $6 \mathrm{~h}$ of age and the unventilated control groups killed at birth with an overdose of IV pentobarbital.

Sample collection. Lung tissues from the right lower lung lobe and liver tissues were snap-frozen for RNA and protein analysis. The right upper lung lobe was inflation fixed at $30 \mathrm{cmH}_{2} \mathrm{O}$ in $4 \%$ paraformaldehyde and used for in situ hybridization. Bronchoalveolar lavage (BAL) was performed on the left lung using $0.9 \% \mathrm{NaCl}$ at $4{ }^{\circ} \mathrm{C}$ until full distension and repeated five times. Plasma was analyzed at $4 \mathrm{~h}$ after delivery for SAA levels since a previous study demonstrated pro-inflammatory cytokine expression at this time period (14).

SAA3. Riboprobe. The sheep SAA3 cDNA clone [pGEMT-sSAA3(8C3)] (8) was cut with Fok I and a 420 nucleotide antisense riboprobe was synthesized using T7 RNA polymerase. This riboprobe produced a 282 nucleotide protected fragment with SAA3 as shown in Fig. $1 A$.

RNA quantitation. Total RNA was isolated using a modified Chomczynski method from lung and liver tissue (16). Ten micrograms of RNA were used for RNase protection assays with the antisense SAA3 riboprobe depicted in Fig. $1 \mathrm{~A}$. Solution hybridization was performed in $80 \%$ deionized formamide, $0.4 \mathrm{M}$ $\mathrm{NaCl}, 2 \mathrm{mM}$ EDTA and 0.04M PIPES, pH 6.6 using a molar excess of $\left[{ }^{32} \mathrm{P}\right]$ UTP labeled probes for $16 \mathrm{~h}$ at $55^{\circ} \mathrm{C}$. Single stranded RNA was digested with RNase A/T1 (Pharmingen, San Diego, CA). RNase was inactivated and the protected RNA was precipitated using RNase inactivation buffer (Ambion, Austin, Texas) and ethanol. The probe for L32, a ribosomal protein mRNA, was included in each assay as an internal standard (8). Protected fragments were resolved on $6 \%$ polyacrylamide $8 \mathrm{M}$ urea gels, visualized by autoradiography and quantified on a Phosphor Imager using Image Quant version 1.2 software (Molecular Dynamics, Sunnyvale, CA). To ensure accurate comparisons between large numbers of samples in different groups, the same set of ventilated only animals were used as "standards" in each experiment. Thus the SAA3 mRNA comparisons in each gel were made relative to the ventilated group. A correction factor was then used to account for experimental variations between gels. For ease of depiction and graphical presentation, the values for the unventilated control group of both preterm and near term animals were arbitrarily set to equal 1 .

In situ hybridization. In situ hybridizations of paraffin-embedded sections were performed using $\left[{ }^{35} \mathrm{~S}\right] \mathrm{UTP}$ labeled probes as previously described (17). The plasmid psSAA(8c3) was digested with NotI for antisense probe (T7 polymerase; Promega) and with $\mathrm{NcoI}$ for sense probe (SP6 polymerase; Promega) synthesis. For hybridization, the sense and the antisense probes were diluted in hybridization buffer to a final concentration of $4.7 \times 10^{4} \mathrm{cpm} / \mu \mathrm{L}$ and incubated at $57^{\circ} \mathrm{C}$. After hybridization, the sections were washed at high stringency because of the high GC content $(55 \%)$ of the riboprobe. A wash buffer containing $50 \%$ formamide, $2 \times$ SSC and $10 \mathrm{mM}$ DTT for $30 \mathrm{~min}$ at $65^{\circ} \mathrm{C}$ was used. The sections were treated with RNase A/T1 to reduce nonspecific binding and subsequently washed in a descending series of SSC solutions ending in a $15 \mathrm{~min}$ wash at room temperature in $0.1 \times \mathrm{SSC} / 1 \mathrm{mM}$ DTT. Tissue sections were photographed under dark-field illumination and
A

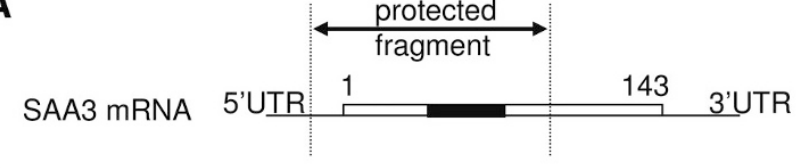

B

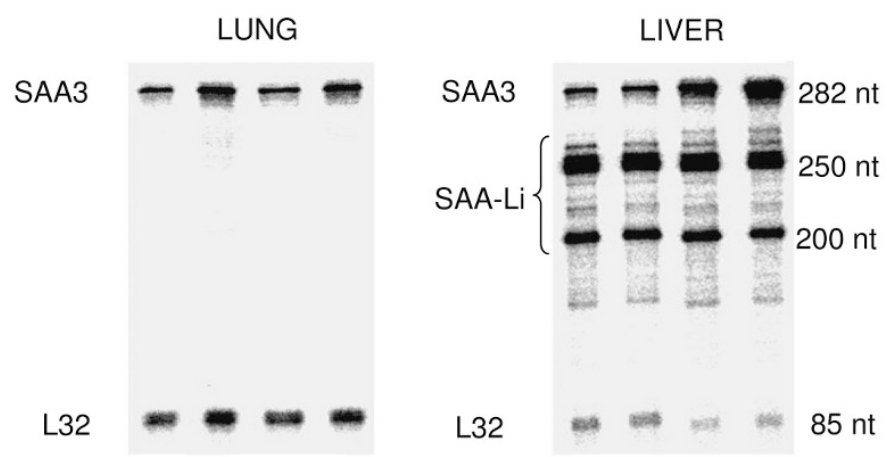

Figure 1. Sheep SAA mRNA isoforms. A) Schematic representation of SAA3 riboprobe in relation to the mRNA. The SAA3 riboprobe protected a 282 nucleotide (nt) fragment which encompassed portions of the $5^{\prime}$ untranslated region (UTR) and the coding sequence of the SAA3 mRNA including a conserved region present among all SAA isoforms (shaded region). The amino acid sequence of the conserved region is DKYFHARGNYDAAQRGPGGVWAA. The numbers 1 through 143 represents the amino acids of the translated SAA3 protein. $B$ ) Representative RNase protection assays of SAA3 and serum amyloid A-Liver inducible (SAA-Li) isoforms using $10 \mu \mathrm{g}$ total RNA from lung and liver of 4 IV (IV) endotoxin-exposed near term animals. SAA3 was detected in both lung and liver whereas SAA-Li isoforms were detected only in the liver.

then counterstained with hematoxylin for morphologic analysis. Controls for specificity of riboprobe binding included lung tissues from preterm and near-term lambs ventilated with no endotoxin exposure and a homologous (sense) probe.

ELISA. The concentration of SAA proteins in the plasma and lung homogenates of near term animals and the bronchoalveolar lavage of preterm animals was measured using a sandwich ELISA kit (Tridelta Diagnostics, New Jersey). The SAA isoform specificity of the ELISA assay is not known. An antibody specifically binding to SAA3 is not available.

Statistics. All values were expressed as means \pm SEM. Analysis of variance (ANOVA) was used for comparison of differences between groups with Student-Newman-Keuls test used for post hoc analysis. The nonparametric Mann-Whitney test was used for two group comparisons. Significance was accepted at $p<0.05$.

\section{RESULTS}

Detection of SAA isoforms. Using the SAA3 riboprobe (Fig. 1A), a single protected fragment (282 nucleotides) corresponding to the full-length SAA3 probe was detected in lung samples (Fig. 1B). In contrast, in the liver, in addition to the 282 nucleotide protected fragment, two other fragments of approximately 250 and 200 nucleotides in length were detected. These additional protected fragments, closely related to SAA3 but different in expression pattern and size, were designated as SAA-Liver inducible (SAA-Li) in this manuscript.

SAA3 mRNA expression in preterm lambs. SAA3 mRNA increased approximately 3 -fold in the lung and liver of ventilated preterm animals compared with unventilated controls (Fig. 2). Compared with controls, SAA3 mRNA increased 64-fold in the lung and 44-fold in the liver in response to intratracheal endotoxin and ventilation. 

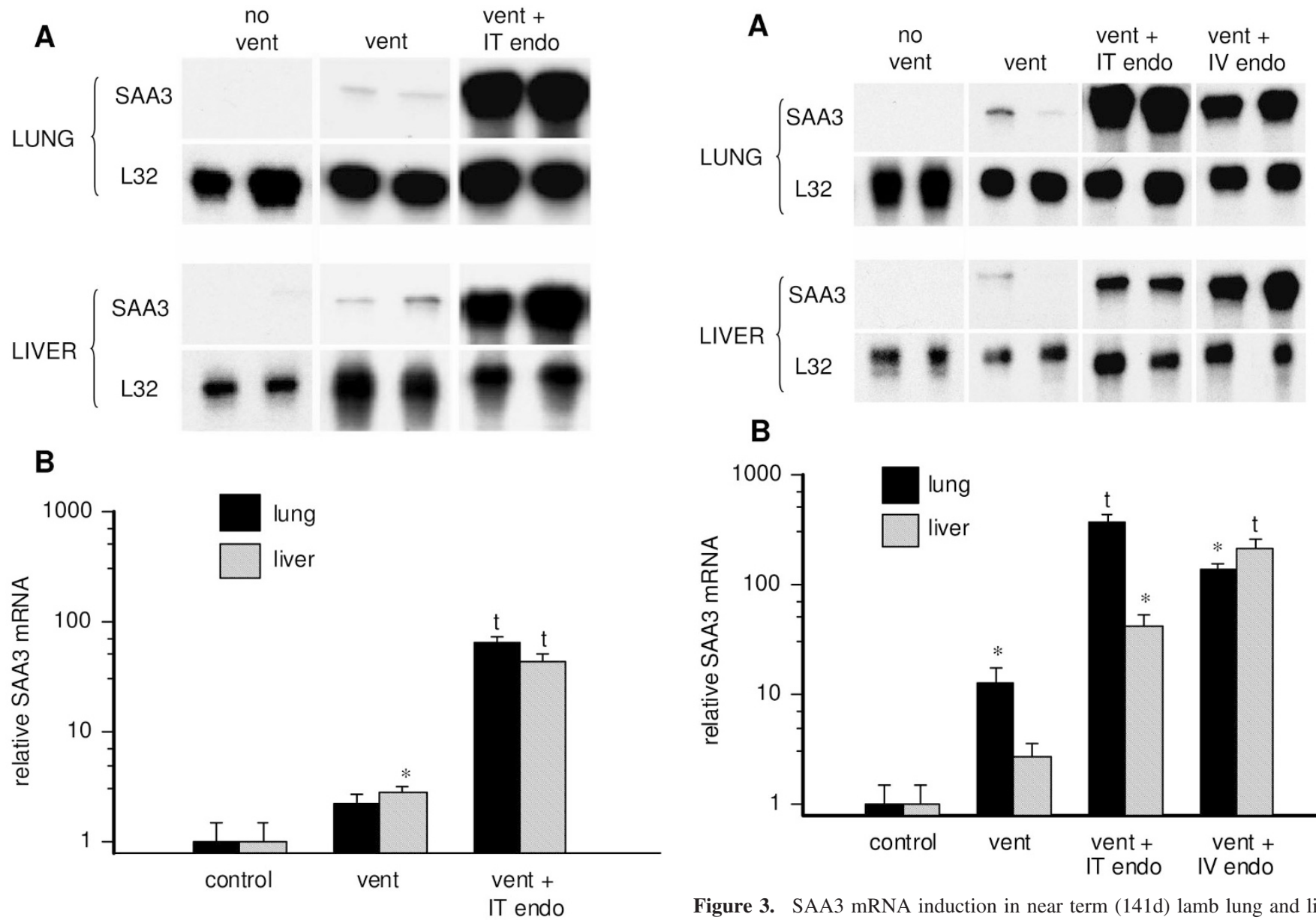

\section{B}

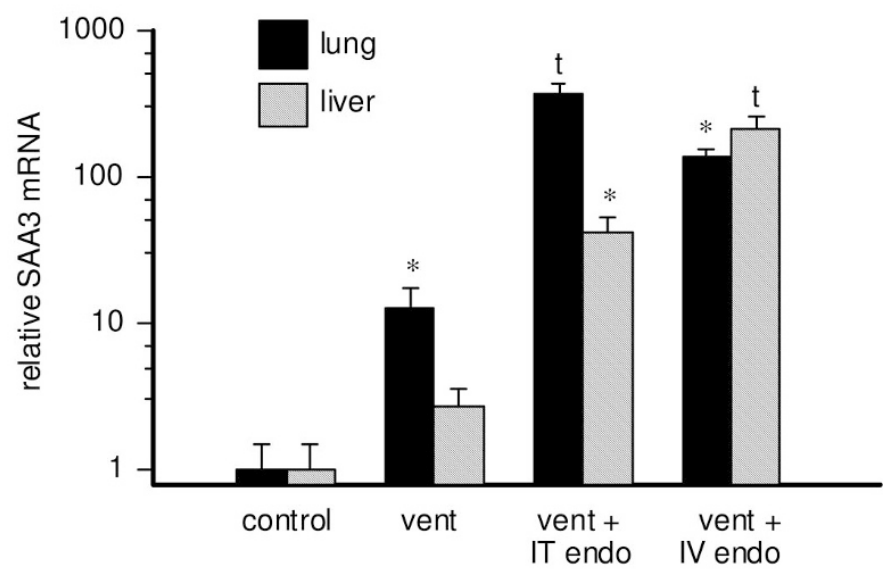

Figure 2. SAA3 mRNA induction in preterm (130d) lamb lung and liver. A) Representative RNase protection assays of SAA3 using $10 \mu \mathrm{g}$ total RNA from lung and liver of two animals per group. B) Quantitation of induction of SAA3 mRNA in response to ventilation and ventilation (vent) + endotoxin (endo) using a log scale (Y-axis). Control animals were not ventilated. SAA3 mRNA values were normalized to L32. The mean SAA3 mRNA signal in the control animals was given a value of 1 and the levels in the treatment groups are expressed as mRNA values relative to controls. Ventilation + intratracheal endotoxin (IT endo) caused the highest increase in SAA3 mRNA in both lung and liver. ( ${ }^{*} p<0.05 v s$. control; $p=0.056$ for the lungs of vent group $v s$. control; ${ }^{\mathrm{t}} p<0.001 v s$. other groups in lung or liver; $n=5$ animals for control and 4-5 animals for the treatment groups; IT, intratracheal).

SAA3 mRNA expression in near term lambs. In response to ventilation alone, SAA3 mRNA increased almost 13-fold in the lung while liver SAA3 mRNA increased 3-fold when compared with unventilated controls (Fig. 3). On exposure to ventilation and intratracheal endotoxin, SAA3 mRNA increased 366-fold in the lung compared with controls while there was a 42-fold induction of SAA3 mRNA in the liver. Exposure to ventilation and IV endotoxin resulted in a 212- and 139-fold induction of SAA3 mRNA in liver and lung, respectively, compared with controls.

SAA-Li mRNA expression in liver of near term lambs. Due to similarity in the magnitude of induction of the 250 and 200 nucleotide SAA-Li fragments, the quantitation of only the 250 nucleotide fragment was reported (Fig. 4). When compared with unventilated controls, SAA-Li mRNA increased 10-fold in the liver of ventilated near term animals. Exposure of these

Figure 3. SAA 3 mRNA induction in near term (141d) lamb lung and liver. A) Representative RNase protection assays of serum amyloid A3 (SAA3) using $10 \mu \mathrm{g}$ total RNA from lung and liver of two animals per group. B) Quantitation of induction of SAA3 mRNA in response to ventilation (vent) and ventilation + endotoxin (endo) shown on a $\log$ scale (Y-axis). Control animals were not ventilated. SAA3 mRNA values were normalized to L32. The mean SAA3 mRNA signal in the control animals was given a value of 1 and the levels in the treatment groups are expressed as mRNA values relative to controls. Ventilation caused a significant increase in SAA3 mRNA in the lung relative to controls. Ventilation + intratracheal endotoxin (IT endo) caused the highest increase in SAA3 mRNA expression in the lung relative to all other lung groups. Ventilation + IT endotoxin significantly increased SAA3 mRNA expression in the liver relative to controls. Ventilation + IV endotoxin produced the highest increase in SAA3 mRNA in the liver relative to all other liver groups. ( ${ }^{*} p<0.05 v s$. control; ${ }^{\mathrm{t}} p<0.001 v s$. other lung or liver groups; $n=5-6$ animals for control and 4-6 animals for the treatment groups; IT, intratracheal; IV, intravenous).

ventilated animals to either intratracheal or IV endotoxin did not produce significant further induction of SAA-Li mRNA in the liver.

Sites of SAA3 expression in lung after IT endotoxin. Ventilation alone induced a low level of expression of SAA3 mRNA in the saline treated near term animals in the bronchial epithelium and vascular smooth muscle (Fig. 5A,B). Exposure to ventilation and intratracheal endotoxin resulted in prominent expression in the bronchial epithelium, bronchial glands and arterial smooth muscle cells (Fig. 5C,D). A high level of expression was also detected in the bronchial epithelium, bronchial glands, and arterial smooth muscle cells in response to ventilation and IV endotoxin (Fig. 5E,F). The perichondrial cells of bronchial cartilage had prominent SAA3 mRNA ex- 
A
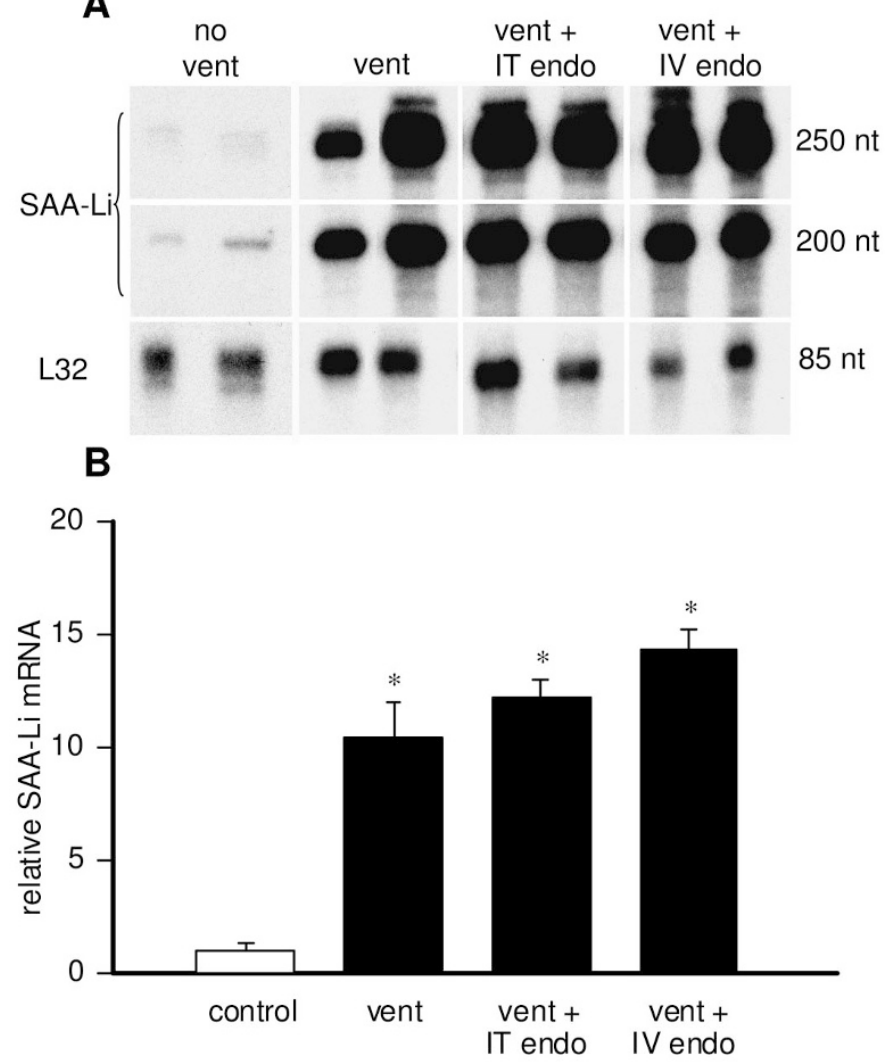

Figure 4. SAA-Li mRNA induction in liver from near term lambs. A) Representative RNase protection assays of serum amyloid A-Liver inducible (SAA-Li) using $10 \mu \mathrm{g}$ total RNA from liver of two animals per group. $B$ ) Quantitation of induction of SAA-Li mRNA in response to ventilation (vent) and ventilation + endotoxin (endo). Control animals were not ventilated. The SAA-Li mRNA values were normalized to L32. The mean SAA-Li mRNA signal in control animals was given a value of 1 and the levels in the treatment groups are expressed as mRNA values relative to controls. The SAA3 mRNA expression in the treatment groups was significantly increased relative to controls. ( ${ }^{*} p<0.001 v s$. control; $n=6$ animals for control and $4-6$ animals for the treatment groups; IT, intratracheal; IV, intravenous; nt, nucleotides).

pression (Fig. 5E,F). This was detected in the lungs of ventilated lambs exposed to either IV or intratracheal endotoxin. The controls had no expression of SAA3 mRNA (Fig. 5G,H). Sporadic expression of SAA3 mRNA was also detected in neutrophils but this expression was much lower than the levels detected in the bronchial epithelium, bronchial glands, perichondrial cells and arterial smooth muscle cells. The pattern of expression was similar for the preterm lambs (data not shown).

SAA protein quantitation. SAA protein was not detectable in the plasma of unventilated or ventilated near term animals using an ELISA kit of unknown SAA specificity. Intratracheal endotoxin induced plasma SAA concentration to $1474 \pm 165$ $\mathrm{ng} / \mathrm{mL}$ in the near term animals whereas IV endotoxin caused plasma SAA levels of $2928 \pm 589 \mathrm{ng} / \mathrm{mL}$. The SAA protein was below detectable levels in the lung homogenates or BAL fluid obtained from near term or preterm lambs exposed to ventilation and endotoxin.

\section{DISCUSSION}

In this study designed to evaluate lung acute phase reactant response, we demonstrate that SAA3 mRNA is robustly in-
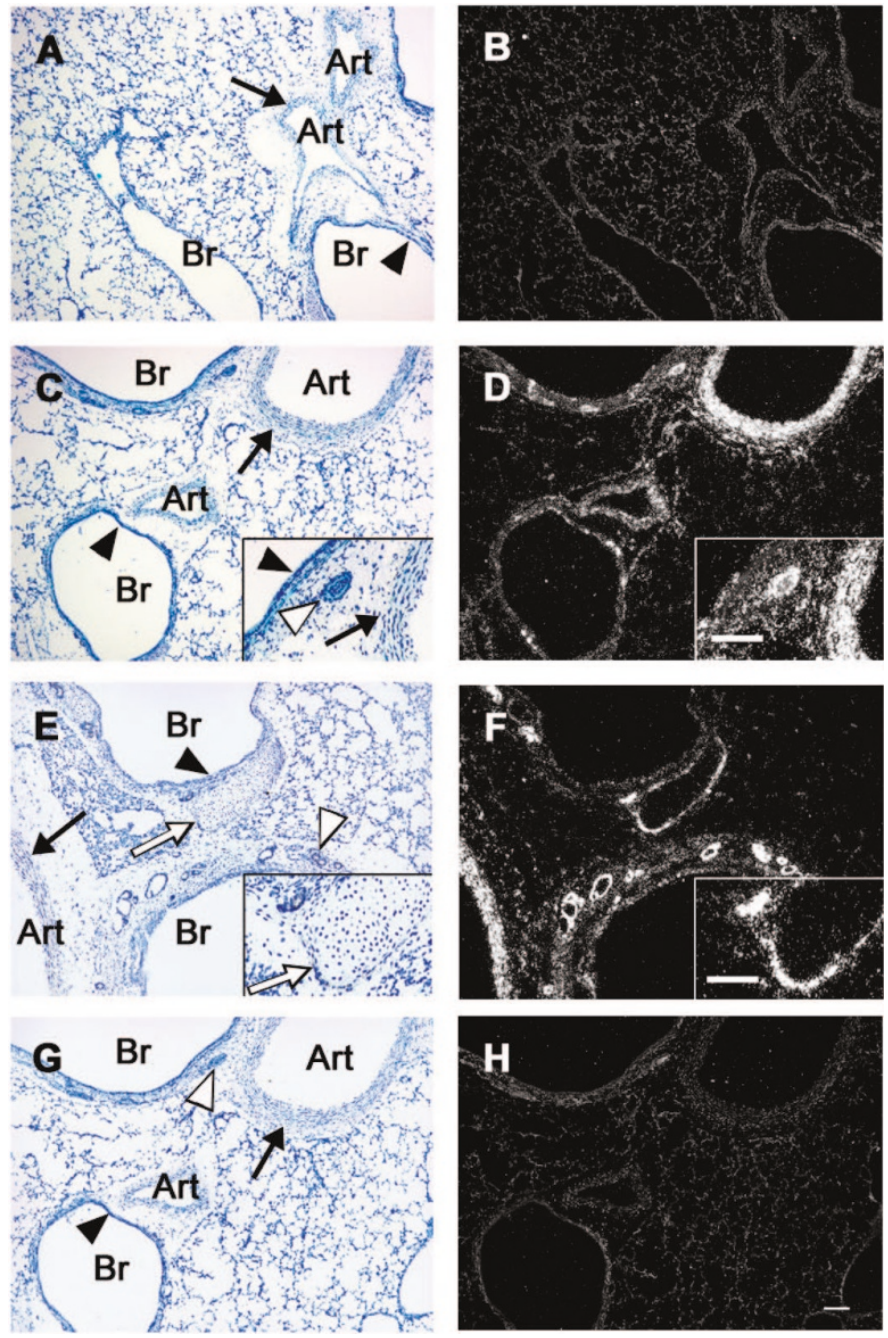

Figure 5. SAA3 mRNA expression in endotoxin-exposed lung. In situ hybridization was performed with $\left[{ }^{35} \mathrm{~S}\right]$ labeled antisense sheep SAA3 riboprobe on lung sections from near term lambs. $(A, B)$ ventilation + IT saline, $(C, D)$ ventilation + IT endotoxin, $(E, F)$ ventilation + IV endotoxin, $(G, H)$ ventilation + IT endotoxin with sense $\left[{ }^{35} \mathrm{~S}\right]$ labeled SAA3 riboprobe (controls). Intense focal expression was seen in the bronchial glands (open arrowhead), bronchial epithelium (closed arrowhead), perichondrial cells of bronchial cartilage (open arrow) and arterial smooth muscle (closed arrow). Insets in $C, D, E$ and $F$ show higher magnification. $A, C, E$ and $G$ are bright-field images and $B, D, F$ and $H$ are corresponding dark-field images (bar represents $100 \mu \mathrm{m})$.

duced postnatally in the lung of both preterm and near term lambs in response to ventilation and endotoxin administration. Regardless of the route of endotoxin administration (intratracheal (IT) or IV), SAA3 mRNA expression was induced in the bronchial epithelium, bronchial glands, perichondrium of bronchial cartilage and vascular smooth muscle of the lung. These experiments suggest that significant induction of expression of the acute phase reactant SAA3 mRNA occurs in the neonatal lung in response to pro-inflammatory stimuli.

The SAA protein family, as described in humans and mice, consists of the acute phase isoforms SAA1, SAA2 and SAA3 and the constitutively expressed SAA4 (18). The SAA3 riboprobe used in our study protected a single full length fragment in the lung which corresponded to SAA3 mRNA. However, in the liver, in addition to this fragment, two other smaller 
protected fragments were detected. These fragments likely represent other SAA isoforms that are inducible (liverinducible) because they were detected in the liver and not lung and were induced by ventilation and endotoxin exposure. We have designated these fragments as SAA-Li (SAA-liver inducible) mRNA in this manuscript. Definitive identification of these isoforms could not be performed because the mRNA sizes of SAA1, 2 and 3 are similar and full length mRNA sequences of ovine SAA isoforms are not available. However, our data demonstrates the differential expression of SAA isoforms in the lung and liver. The "noninjurious" ventilator strategy used in this study caused only a mild increase in liver SAA3 mRNA in the near term animals in response to mechanical ventilation alone. However, a more impressive induction of the SAA-Li isoforms was detected in these animals demonstrating a significant systemic acute phase reactant (APR) response to mechanical ventilation.

The liver is the main source of expression of SAA1 and SAA2 whereas SAA3 is produced principally in extra hepatic sites $(4,6)$. Expression of SAA3 mRNA was previously demonstrated in the lungs of adult mice following lipopolysaccharide (LPS) injection $(6,7)$. We found that sheep SAA3 mRNA expression was induced both in the lung and the liver whereas SAA-Li mRNA expression was induced in liver but not in the lung. As expected, a systemic pro-inflammatory stimulus (IV endotoxin) caused a more prominent SAA3 mRNA induction in liver than lung, while a pulmonary inflammatory stimulus (intratracheal endotoxin) caused a more prominent lung SAA3 mRNA expression than liver expression. The increased oxygen exposure in the mechanically ventilated animals can cause oxidative lung injury. This may have contributed to the increased SAA3 mRNA expression detected in these animals. These results indicate that the lung and liver of the developing sheep both participate in the APR response, with the magnitude of the response in each organ dependent on the type and route of pro-inflammatory stimulus.

The SAA proteins are apolipoproteins, which during the acute phase response bind to HDL fraction $3\left(\mathrm{HDL}_{3}\right)(4,19-$ $21)$ and stimulate the recruitment of inflammatory cells $(22,23)$ and the release of pro-inflammatory cytokines (24). Although the precise function of amyloid A proteins is unknown, they are thought to play an important role in modulating the innate host defense against inflammatory agents and are involved in cholesterol transport and metabolism $(19,25-27)$. In humans, SAA3 has been postulated to be a pseudogene in some studies $(28,29)$, although in another study the human SAA3 gene was expressed in mammary gland epithelial cells in response to either prolactin or LPS (30). It is not known if the different isoforms have distinct functions. A number of alleles have been reported for some isoforms thus making the SAA family a large and complex array of proteins that may be multifunctional (18). Because SAA3 mRNA expression is induced in inflammatory models of the developing sheep lung, the presence of this isoform expressed in the lung of preterm humans may warrant further investigation.

In this study, SAA3 expression was detected in bronchial epithelium, bronchial glands, perichondrial cells of bronchial cartilage, vascular smooth muscle and, to a lesser extent, in inflammatory cells. Perichondrial cell and vascular smooth muscle expression of SAA3 were not detected in our previous study of antenatal endotoxin exposure (8). It is possible that the different design of this study, which involved exposure of the lamb lungs to mechanical ventilation, increased partial pressures of oxygen, higher pulmonary blood flow and intratracheal or IV endotoxin, preferentially induced SAA3 mRNA in the perichondrium and vascular smooth muscle.

Pro-inflammatory cytokines, in particular IL-1, IL-6 and tumor necrosis factor alpha (TNF- $\alpha$ ) stimulate SAA synthesis during the adult acute phase response $(19,31,32)$. We previously reported increased lung mRNA expression of these cytokines by $2 \mathrm{~h}$ in ventilated preterm lambs compared with unventilated fetal controls (11). In addition, we demonstrated that exposure to ventilation and IT endotoxin causes a modest increase in lung IL-1 $\beta$ and IL-6 mRNAs in preterm and near term lambs (23- and 13-fold respectively) (14). We now show a much more robust expression of SAA3 mRNA in the lungs of these animals (366 fold increase). The SAA-Li isoform was induced in the liver by ventilation and oxygen exposure with minimal incremental response to endotoxin suggesting that different SAA isoforms have different mechanisms of induction.

A limitation of this study is the lack of a specific anti-SAA3 antibody. Plasma SAA levels increased after ventilation and IT or IV endotoxin within $4 \mathrm{~h}$ of exposure. This plasma SAA was not of lung origin since the BALF and lung homogenate SAA3 was not detected by the commercially available antibody used.

In summary, we demonstrated selective lung expression of SAA3 mRNA in preterm lambs, rapid induction in the lung in response to both mechanical ventilation and endotoxin stimulation as well as a systemic acute phase reactant response.

Acknowledgments. The authors thank Dr. Jean Sipe (National Institutes of Health) for her critical review of this manuscript.

\section{REFERENCES}

1. Ceciliani F, Giordano A, Spagnolo V 2002 The systemic reaction during inflammation: the acute-phase proteins. Protein Pept Lett 9:211-223

2. Suffredini AF, Fantuzzi G, Badolato R, Oppenheim JJ, O'Grady NP 1999 New insights into the biology of the acute phase response. J Clin Immunol 19:203-214

3. Moseley PL 1998 Heat shock proteins and the inflammatory response. Ann N Y Acad Sci 856:206-213

4. Uhlar CM, Whitehead AS 1999 Serum amyloid A, the major vertebrate acute-phase reactant. Eur J Biochem 265:501-523

5. Webb CF, Tucker PW, Dowton SB 1989 Expression and sequence analyses of serum amyloid A in the Syrian hamster. Biochemistry 28:4785-4790

6. Meek RL, Benditt EP 1986 Amyloid A gene family expression in different mouse tissues. J Exp Med 164:2006-2017

7. Benditt EP, Meek RL 1989 Expression of the third member of the serum amyloid A gene family in mouse adipocytes. J Exp Med 169:1841-1846

8. Kallapur SG, Kramer BW, Moss TJ, Newnham JP, Jobe AH, Ikegami M, Bachurski CJ 2003 Maternal glucocorticoids increase endotoxin-induced lung inflammation in preterm lambs. Am J Physiol Lung Cell Mol Physiol 284:L633-L642

9. Apisarnthanarak A, Holzmann-Pazgal G, Hamvas A, Olsen MA, Fraser VJ 2003 Ventilator-associated pneumonia in extremely preterm neonates in a neonatal intensive care unit: characteristics, risk factors, and outcomes. Pediatrics 112:1283-1289

10. Gaynes RP, Edwards JR, Jarvis WR, Culver DH, Tolson JS, Martone WJ 1996 Nosocomial infections among neonates in high-risk nurseries in the United States. National Nosocomial Infections Surveillance System. Pediatrics 98:357-361

11. Naik AS, Kallapur SG, Bachurski CJ, Jobe AH, Michna J, Kramer BW, Ikegami M 2001 Effects of ventilation with different positive end-expiratory pressures on cytokine expression in the preterm lamb lung. Am J Respir Crit Care Med 164:494-498

12. Slutsky AS 1999 Lung injury caused by mechanical ventilation. Chest 116:9S-15S. 
13. Dreyfuss D, Saumon G 1998 Ventilator-induced lung injury: lessons from experimental studies. Am J Respir Crit Care Med 157:294-323

14. Kramer BW, Ikegami M, Jobe AH 2002 Intratracheal endotoxin causes systemic inflammation in ventilated preterm lambs. Am J Respir Crit Care Med 165:463-469

15. Davis AJ, Jobe AH, Hafner D, Ikegami M 1998 Lung function in premature lambs and rabbits treated with a recombinant SP-C surfactant. Am J Respir Crit Care Med 157:553-559

16. Bachurski CJ, Pryhuber GS, Glasser SW, Kelly SE, Whitsett JA 1995 Tumor necrosis factor-alpha inhibits surfactant protein C gene transcription. J Biol Chem 270:1940219407

17. Wert SE, Glasser SW, Korfhagen TR, Whitsett JA 1993 Transcriptional elements from the human SP-C gene direct expression in the primordial respiratory epithelium of transgenic mice. Dev Biol 156:426-443

18. Sipe J 1999 Revised nomenclature for serum amyloid A (SAA). Nomenclature Committee of the International Society of Amyloidosis. Part 2. Amyloid 6:67-70

19. Jensen LE, Whitehead AS 1998 Regulation of serum amyloid A protein expression during the acute-phase response. Biochem J 334:489-503.

20. Hoffman JS, Benditt EP 1982 Changes in high density lipoprotein content following endotoxin administration in the mouse. Formation of serum amyloid protein-rich subfractions. J Biol Chem 257:10510-10517

21. Meek RL, Eriksen N, Benditt EP 1992 Murine serum amyloid A3 is a high density apolipoprotein and is secreted by macrophages. Proc Natl Acad Sci U S A 89:7949_ 7952

22. Badolato R, Wang JM, Murphy WJ, Lloyd AR, Michiel DF, Bausserman LL, Kelvin DJ, Oppenheim JJ 1994 Serum amyloid A is a chemoattractant: induction of migration, adhesion, and tissue infiltration of monocytes and polymorphonuclear leukocytes. J Exp Med 180:203-209

23. Badolato R, Johnston JA, Wang JM, McVicar D, Xu LL, Oppenheim JJ, Kelvin DJ 1995 Serum amyloid A induces calcium mobilization and chemotaxis of human monocytes by activating a pertussis toxin-sensitive signaling pathway. J Immunol 155:4004-4010

24. He R, Sang H, Ye RD 2003 Serum amyloid A induces IL-8 secretion through a G protein-coupled receptor, FPRL1/LXA4R. Blood 101:1572-1581

25. Liang JS, Sipe JD 1995 Recombinant human serum amyloid A (apoSAAp) binds cholesterol and modulates cholesterol flux. J Lipid Res 36:37-46

26. Banka CL, Yuan T, de Beer MC, Kindy M, Curtiss LK, de Beer FC 1995 Serum amyloid A (SAA): influence on HDL-mediated cellular cholesterol efflux. J Lipid Res 36:1058-1065

27. Lindhorst E, Young D, Bagshaw W, Hyland M, Kisilevsky R 1997 Acute inflammation, acute phase serum amyloid $\mathrm{A}$ and cholesterol metabolism in the mouse. Biochim Biophys Acta 1339:143-154

28. Urieli-Shoval S, Cohen P, Eisenberg S, Matzner Y 1998 Widespread expression of serum amyloid A in histologically normal human tissues. Predominant localization to the epithelium. J Histochem Cytochem 46:1377-1384

29. Kluve-Beckerman B, Drumm ML, Benson MD 1991 Nonexpression of the human serum amyloid A three (SAA3) gene. DNA Cell Biol 10:651-661

30. Larson MA, Wei SH, Weber A, Weber AT, McDonald TL 2003 Induction of human mammary-associated serum amyloid A3 expression by prolactin or lipopolysaccharide. Biochem Biophys Res Commun 301:1030-1037

31. Steel DM, Whitehead AS 1994 The major acute phase reactants: C-reactive protein, serum amyloid $\mathrm{P}$ component and serum amyloid A protein. Immunol Today 15:81-88

32. Benigni F, Fantuzzi G, Sacco S, Sironi M, Pozzi P, Dinarello CA, Sipe JD, Poli V, Cappelletti M, Paonessa G, Pennica D, Panayotatos N, Ghezzi P 1996 Six different cytokines that share GP130 as a receptor subunit, induce serum amyloid A and potentiate the induction of interleukin-6 and the activation of the hypothalamuspituitary-adrenal axis by interleukin-1. Blood 87:1851-1854 